\title{
Anisotropy and attenuation of crosshole channel waves from the Antrim Shale gas play, Michigan Basin
}

\author{
Enru Liu ${ }^{\text {a, * }}$, John H. Queen ${ }^{\text {b,1, V. Dale Cox }}{ }^{\text {b }}$ \\ ${ }^{a}$ British Geological Survey, Murchison House, West Mains Road, Edinburgh, Scotland EH9 3LA, UK \\ b Conoco, P.O. Box 1267, Ponca City, OK 74603, USA
}

Received 29 October 1997; accepted 22 October 1999

\begin{abstract}
We analyze the crosshole data from the Antrim Shale gas play at the MIT test site in the Michigan Basin. A crosshole seismic logging analysis has revealed the presence of strong transverse isotropy possibly due to the alignment of clay platelets along the bedding plane or sedimentary bedding, and strong continuity in the depth interval covered in this study. We find that the data are dominated by channel waves associated with low velocity zones (waveguides) identified in the sonic logs. Channel waves are characterized by their unique characteristics, such as dispersion and amplitude variation with depth. The channel-wave analysis has revealed the possible presence of azimuthal anisotropy at the top of the depth covered in this survey, which may be related to fracturing in the Antrim Shale formation. The data also show strong attenuation of S-waves characterized by very low frequency contents which may be due to viscoelastic properties of shaly sands or scattering by fractures. However, direct estimates of fracture parameters are not possible due to the limited data available. Finally, we have modeled the data with synthetic seismograms using a model with a 30\% anisotropy. (c) 2000 Elsevier Science B.V. All rights reserved.
\end{abstract}

Keywords: Anisotropy; Attenuation; Channel waves; Seismic waves; Michigan Basin

\section{Introduction}

The continuity logging method of measurements between boreholes has been used for detecting and characterizing channel waves and exploring their potential applications in different geological environments, and is currently being used for reservoir continuity in hydrocarbon fields. The concepts and applications are well

\footnotetext{
* Corresponding author. Tel.: +44-131-650-0362; fax: +44-131-667-1877; e-mail: e.liu@bgs.ac.uk

${ }^{1}$ E-mail: john.h.queen@usa.conoco.com.
}

documented by Liu et al. (1992), Dresen and Rüter (1994) and others for coal-seams, and by Krohn (1992), Turpening et al. (1992), Parra et al. (1996) and others for oil/gas reservoirs. The technique is now known as crosshole continuity logging or crosshole seismic logging, and the idea is based on the use of seismic channel waves, which have been widely used in the coal industry (where the method is known as in-seam seismics) to map the continuity of coal seams. Previous observations of channel-waves in crosshole surveys include examples from the Conoco borehole test facility, Oklahoma (Liu et 
al., 1991; Lines et al., 1992, 1995), and Gypsy test site, Oklahoma (Turpening et al., 1992; Parra et al., 1996). Synthetic examples were given by Zhong and Worthington (1994) and Parra (1996). Lou and Crampin (1991; 1992) have provided a theoretical basis for channelwave propagation in anisotropic waveguides.

This paper deals with the analysis of crosshole data recorded in the Antrim Shale formation at the MIT test site, Michigan Basin. The data were recorded as part of a collaboration between Conoco and MIT's Earth Resource Laboratory. The main objective of this analysis was to demonstrate the applicability of crosshole channel waves to determine bed continuity in the Antrim Shale formation, and to assess the potential of using channel waves to characterize fractures. This study makes two contributions: Firstly, the concept of the crosshole seismic logging method (CHSL) is introduced to estimate the horizontal formation velocities directly by measuring the travel-time of the waves between source and receivers located at the same depth. Compared with the borehole sonic log (vertical) travel-times, we found that the horizontal P-wave velocities are about 30\% higher than the vertical P-wave velocities. Such a large difference in velocities in different directions is regarded as a direct indication of bedding-induced anisotropy in the Antrim Shale [commonly referred to as transverse isotropy with a vertical axis of symmetry (TIV)]. Secondly, we analyze the observed data in terms of velocity dispersion, attenuation and particle-motion, and suggest that channel waves are observed and are useful for the formation continuity logging. As production in the Antrim Shale is known to be fracture related (Cain et al., 1996), we attempted to interpret the channel waves in terms of fracture-induced seismic anisotropy. However, it was found that the azimuthal anisotropy [or transverse isotropy with a horizontal axis of symmetry (TIH)] is less obvious, but exists, particularly at the top of the interval examined in this survey. This is indicated primarily by the coupling of SH-waves onto in-line components.
Such a combination of TIV and TIH anisotropies results in an orthorhombic anisotropy symmetry as may be expected in most sedimentary rocks (Bush and Crampin, 1991). Finally, we conclude our studies by modeling the observations using synthetic seismograms, which provide further support to our interpretation.

\section{Geological setting and data description}

The geological setting of the Antrim Shale gas play in the Michigan Basin has been described by Sriram et al. (1991) and Cain et al. (1996). A brief summary of these descriptions are given below. The upper Devonian Antrim Shale is an organic-rich marine shale that provides significant U.S. gas reserves. In June 1994, gas production reached 315 MMCFD from approximately 3700 wells, and is expected to increase to $500 \mathrm{MMCFD}$, equivalent to $1 \%$ of U.S. output (Michigan Geological Survey). The productive trend, which covers 700 square miles, occurs near the formation's northern subcrop in the Michigan Basin, and is structurally characterized by gentle basin-ward $\operatorname{dip}\left(\leq 2^{\circ}\right)$. The Antrim Shale is a fractured, algae-rich, highly siliceous, pyritic shale with minor inter-particle porosity. Three factors contribute to the unconventional nature of the gas play: (1) methane desorption from kerogen; (2) orthogonal regional fractures; and (3) a portion of the gas is self-sourced from a low thermal maturity rock.

Two dominant fracture sets, exhibited in both outcrops and the subsurface, provide the essential reservoir permeability in the Antrim Shale. Both sets are characterized by fairly linear traces and near vertical dips, and exhibit little or no offset. The two fracture sets form a nearly orthogonal fracture pattern in plan view with each set showing an average fracture spacing of approximately three feet. Such characteristics are typical of regional fractures which develop independently of local structure (Cain et al., 1996). Abutting the relationships indicate that most of the northwest-striking fractures formed 
by natural hydraulic fracturing as hydrocarbons were generated in the organic shales during the late Palaeozoic subsidence of the Michigan Basin. These NW-striking fractures developed under the influence of the Alleghenian orogenic stresses and are generally analogous to the cross-fold fractures in the Devonian strata of the Appalachian Basin. The NE-striking fractures formed as a result of cooling and unloading during basin uplift in response to local reversal of the minimum and intermediate principal stresses. These later NE fractures tend to have short, curving traces. Despite the existence of regional fracture sets, well productivity can vary greatly over a short distance.
This study focuses on the depth interval from $900 \mathrm{ft}(270 \mathrm{~m})$ to $1250 \mathrm{ft}(380 \mathrm{~m})$ covering the Antrim Shale formation. During the field experiment, 35 sources were displayed between 930 $\mathrm{ft}(280 \mathrm{~m})$ and $1210 \mathrm{ft}(370 \mathrm{~m})$, and 36 threecomponent (3-C) receivers covered the interval between $938 \mathrm{ft}(290 \mathrm{~m})$ and $1210 \mathrm{ft}(380 \mathrm{~m})$. The offset, or interwell distance, between the source and the receiver boreholes was $2000 \mathrm{ft}$ $(610 \mathrm{~m})$, which is significantly greater than the depth coverage by a factor of almost 7 . The raypaths are therefore almost horizontal with the largest angle from the horizontal direction of only $\tan ^{-1}(272 / 2000) \simeq 8^{\circ}$ (assuming a straight line raypath). The source used in the
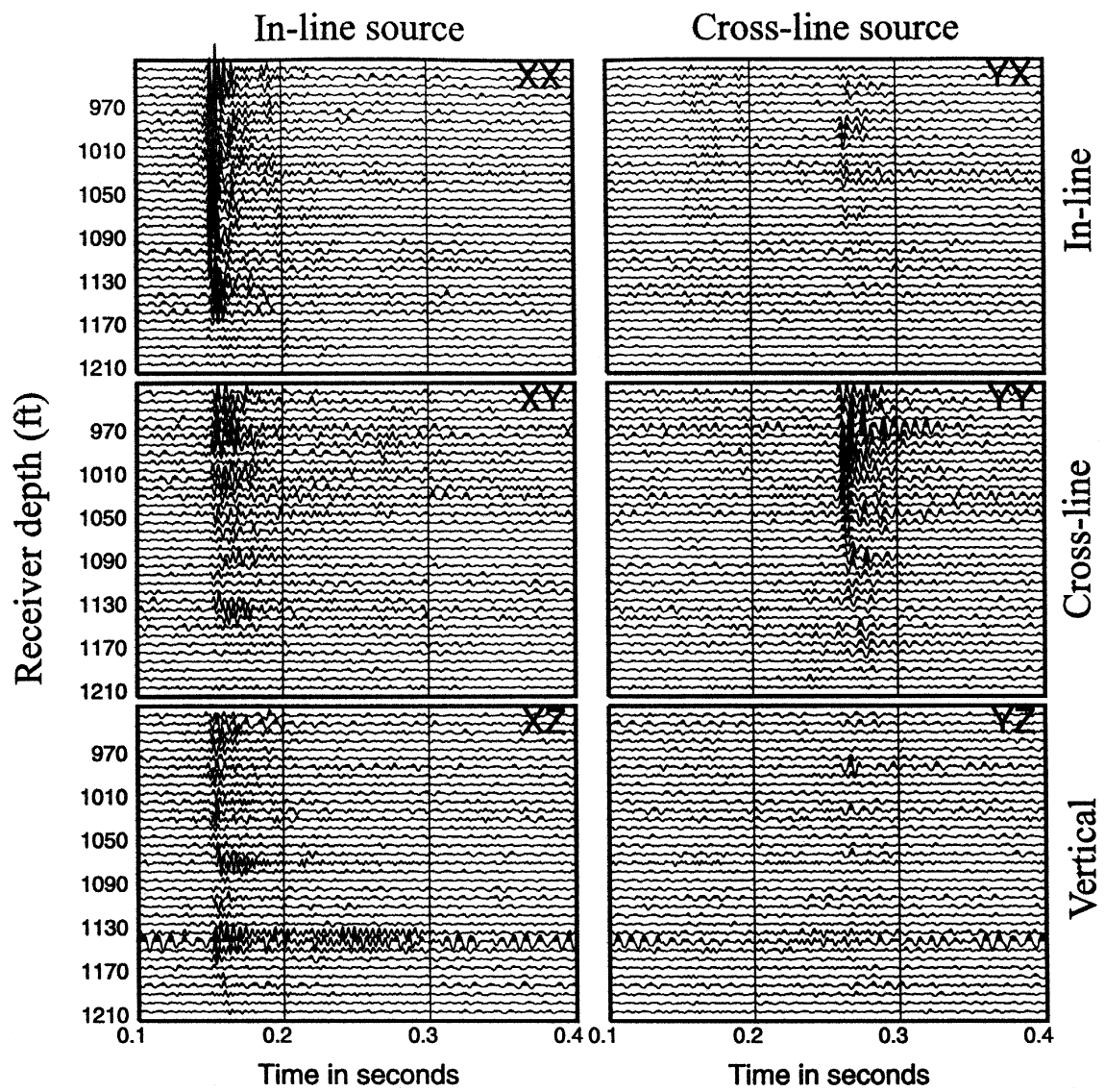

Fig. 1. Representative common-source gather for the source at a depth of $1002 \mathrm{ft}$ (305 m). The data are displayed in the six-component format. Those in the left column are from the in-line sources, and those in the right column are from the cross-line sources. The first and second letters at the top right corner of each display indicate the source and receiver orientations, respectively. 
experiment was a high frequency Conoco-designed rotary source, which generates circular motions which can be decomposed into pure horizontal radial and transverse directions (Hardage, 1992; Cole, 1997). Liu et al. (1991) have shown field examples demonstrating that rotary sources can generate very high quality shear-wave data. The same type of sources have been used in several other crosshole experiments (e.g., Lines et al., 1992, 1995).

Fig. 1 displays a typical plot of raw six-component (6-C) seismograms after rotary source decomposition for a common-source gather with the source at the depth of $1002 \mathrm{ft}(305 \mathrm{~m})$. The left column of 3-C seismograms with $\mathrm{XX}, \mathrm{XY}$ and $\mathrm{XZ}$ are from in-line sources, and the right column of 3-C seismograms with YX, YY and YZ are from cross-line sources. The first letter denotes the source orientation, and the second the receiver orientation. Several features are immediately obvious in Fig. 1. The predominant feature is that $\mathrm{P}$ - and $\mathrm{S}$-waves are completely separated: $\mathrm{P}$-waves appear primarily in the $\mathrm{XX}$ (or radial) components from the in-line sources, and S-waves appear in YY (or transverse) component from the crossline sources. This is not wholly expected, and may be related to the rotary source decomposition. Another feature in Fig. 1 is the low frequency content of $\mathrm{S}$-waves in comparison with $\mathrm{P}$-waves. The following analysis and synthetic modeling suggests that the absence of $\mathrm{S}$-waves in the radial and vertical components from in-line sources may be due to the strong attenuation of S-waves. The third feature is the strong amplitude variation with depth despite the fact that rays deviated from the horizontal by less than $10^{\circ}$. These amplitude variations with depth as seen in Fig. 1 coincide with two low velocity zones. There is also a small energy leaking onto the radial components from the crosshole-line sources for shallow receivers, whereas for deep receivers, there seems to be little coupled energy. The coupled energy is normally regarded as a direct indication of azimuthal anisotropy, but it can also be caused by source coupling.

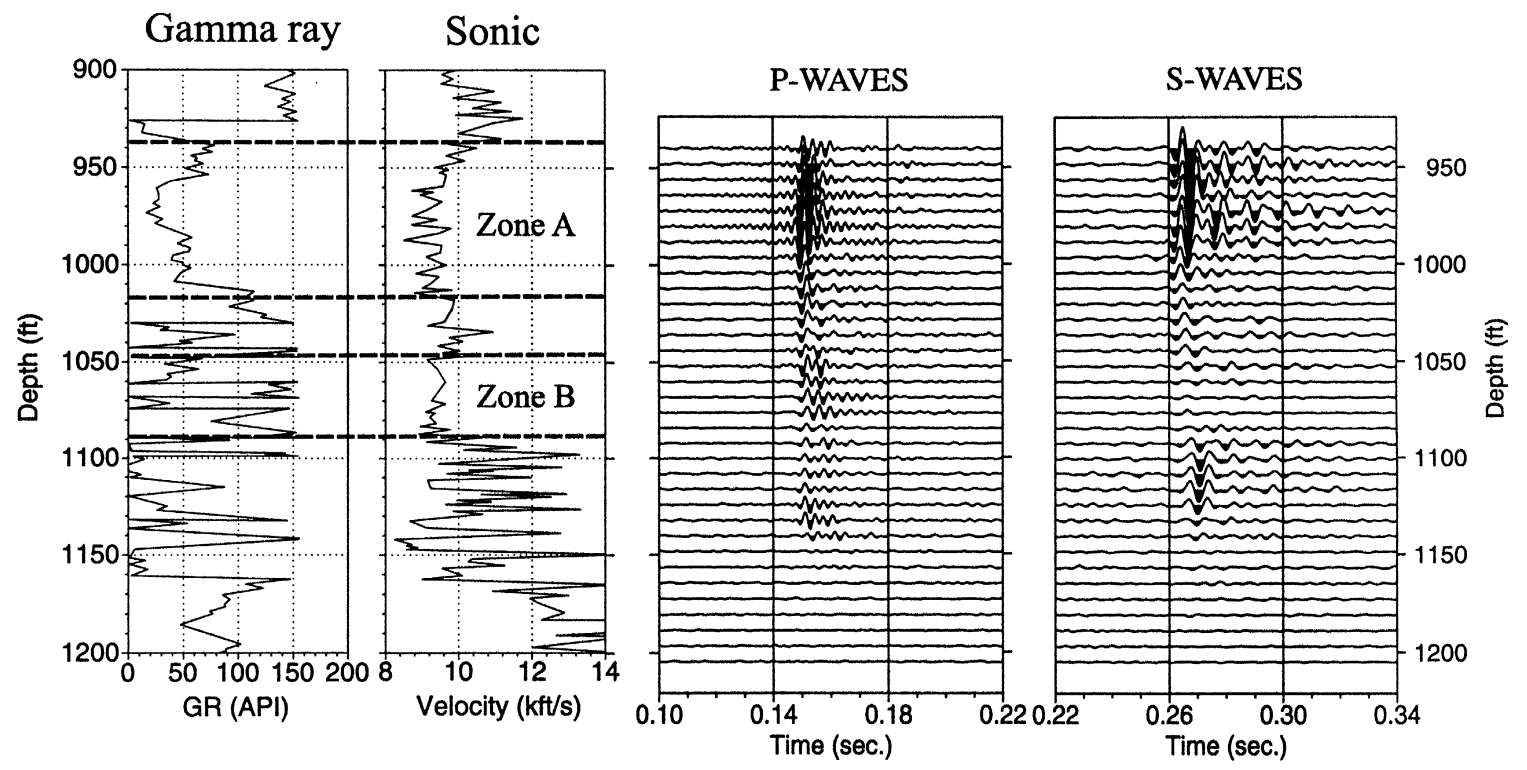

Fig. 2. Gamma ray (left column) and sonic (middle column) logs measured at the receiver borehole. The third column displays the observed P-wave data from the XX-components (e.g., in-line or X-components from in-line sources) with source and receivers located at the same depth, and the fourth column displays the observed S-wave data from the YY-components (i.e., cross-line or Y-components from cross line sources). True relative amplitudes are shown. Two low-velocity zones marked A and B are also shown. 


\section{Crosshole seismic log analysis}

\subsection{Sonic $\log$ and CHSL velocities}

Fig. 2 shows a comparison of the recorded crosshole $\mathrm{P}$-waves from $\mathrm{XX}$-components and $\mathrm{S}$-waves $\mathrm{YY}$-components with gamma ray and sonic logs. The seismograms were plotted in a such way that the sources and receivers are at the same levels (depths), so that horizontal seismic velocities can be directly measured. Amplitude variation with depth and the corresponding velocity profiles in Fig. 2 suggest that the observed wavefields are dominated by channel waves and this will be discussed in Section 4. The comparison of the sonic log vertical velocity with the CHSL horizontal velocity is shown in Fig. 3. (The solid lines in Fig. 3 are later used to build a layered model which is used to

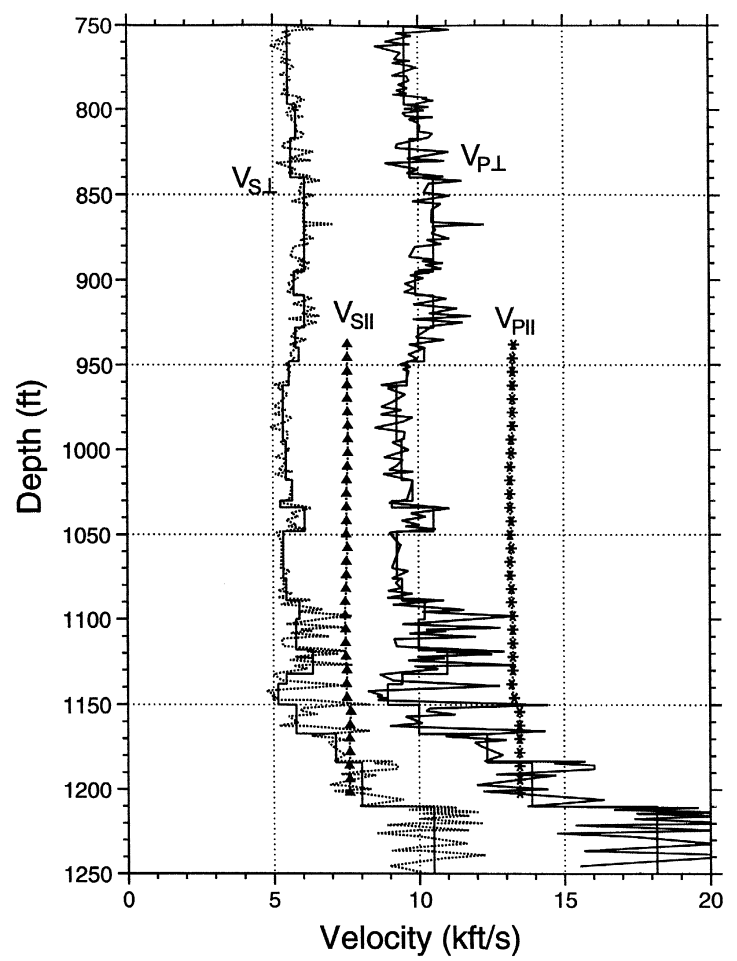

Fig. 3. Comparison of vertical $\mathrm{P}$-wave velocities from sonic logs (lines) and horizontal velocities from CHSL measurements (symbols). $V_{\mathrm{P} \|}$ and $V_{\mathrm{P} \perp}$ are the horizontal and vertical P-wave velocities. $V_{\mathrm{S} \|}$ and $V_{\mathrm{S} \perp}$ are the horizontal and vertical $S$-wave velocities. calculate synthetic seismograms.) Note that the measured CHSL horizontal velocities in Fig. 3 do not show the expected low velocity zones as seen in sonic logs. This is caused by the inaccuracy in travel time picking in the data. The average horizontal P-wave velocity $V_{\mathrm{P} \|}$ between $950 \mathrm{ft}(290 \mathrm{~m})$ and $1100 \mathrm{ft}(335 \mathrm{~m})$ from the CHSL measurement is $13000 \mathrm{ft} / \mathrm{s}(3960$ $\mathrm{m} / \mathrm{s}$ ) (lines with stars), and the average vertical $\mathrm{P}$-wave velocity $V_{\mathrm{P} \perp}$ from the sonic $\log$ is $9700 \mathrm{ft} / \mathrm{s}(2960 \mathrm{~m} / \mathrm{s})$ (solid lines). This is a strong indication of the bedding-induced TIV anisotropy. The degree of anisotropy (or DOA) is defined as $\mathrm{DOA}=\left(V_{\|}-V_{\perp}\right) / V_{\text {mean }}$, where $V_{\|}$is the horizontal velocity, $V_{\perp}$ is the vertical velocity, and $V_{\text {mean }}$ is the mean velocity, i.e., $V_{\text {mean }}=(1 / 2)\left(V_{\|}+V_{\perp}\right)$. We can easily see that the P-wave DOA from our analysis above is approximately $30 \%$. Similarly, the DOA for $\mathrm{S}$-waves is about $38 \%$.

\subsection{Estimation of anisotropy parameters}

A TIV medium is described by five independent elastic constants. Four of the five elastic constants can be determined by:

$C_{11}=\rho V_{\mathrm{P} \|}^{2}$,

$C_{33}=\rho V_{\mathrm{P} \perp}^{2}$,

$C_{66}=\rho V_{\mathrm{S} \|}^{2}$,

$C_{44}=\rho V_{\mathrm{S} \perp}^{2}$,

and $C_{12}=C_{11}-C_{66}$, and $C_{55}=C_{44}$. Where $V_{\mathrm{P} \|}$ and $V_{\mathrm{P} \perp}$ are the horizontal and vertical P-wave velocities. $V_{\mathrm{S} \|}$ and $V_{\mathrm{S} \perp}$ are horizontal and vertical S-wave velocities. The estimation of the fifth independent elastic constant $C_{13}$ requires measurement of $\mathrm{P}$ - and $\mathrm{S}$-wave velocity at an off-axis angle. Ideally, measurements at $45^{\circ}$ from symmetry plane would be useful as there is an explicit expression for $C_{13}$. However, since in this experiment, the raypaths are almost horizontal with the largest angle from the horizontal is only $8^{\circ}$, a numerical solution to the KelvinChristoffel equation has to be obtained to esti- 
mate $C_{13}$ following Helbig (1994). It is convenient to describe anisotropy in terms of the anisotropy parameters in Thomsen (1986) as defined below:

$\varepsilon=\frac{C_{11}-C_{33}}{2 C_{33}}=\frac{V_{\mathrm{P} \|}^{2}-V_{\mathrm{P} \perp}^{2}}{2 V_{\mathrm{P} \perp}^{2}}$,

$\gamma=\frac{C_{66}-C_{44}}{2 C_{44}}=\frac{V_{\mathrm{S} \|}^{2}-V_{\mathrm{S} \perp}^{2}}{2 V_{\mathrm{S} \perp}^{2}}$,

$\delta=\frac{\left(C_{13}+C_{44}\right)^{2}-\left(C_{33}-C_{44}\right)^{2}}{2 C_{33}\left(C_{33}-C_{44}\right)}$

$\varepsilon$ and $\gamma$ are, respectively, the measurements of $\mathrm{P}$ - and $\mathrm{S}$-wave anisotropy. From Fig. 3, we can obtain an average $V_{\mathrm{P} \|}=13000 \mathrm{ft} / \mathrm{s}(3960 \mathrm{~m} / \mathrm{s})$, $V_{\mathrm{P} \perp}=9700 \mathrm{ft} / \mathrm{s}(2960 \mathrm{~m} / \mathrm{s}), V_{\mathrm{S} \|}=7500 \mathrm{ft} / \mathrm{s}$ $(2290 \mathrm{~m} / \mathrm{s}), V_{\mathrm{S} \perp}=5100 \mathrm{ft} / \mathrm{s}(1550 \mathrm{~m} / \mathrm{s})$, and then use Eqs. (2a), (2b) and (2c) to estimate Thomsen's anisotropic parameters: $\varepsilon=0.39, \gamma$ $=0.58$ and $\delta=0.24$. In order to compare these with other results, Table 1 summarizes some measurements of anisotropy in other shale formations. $\varepsilon$ or P-wave anisotropy in the Antrim Shale is similar to the other shales. However, $\gamma$ or $\mathrm{S}$-wave anisotropy and $\delta$ have a wide range of values.

Table 1

A comparison of Thomsen's parameters for various shales

\begin{tabular}{llll}
\hline Type of shales & $\varepsilon$ & $\gamma$ & $\delta$ \\
\hline Antrim Shale $^{\mathrm{a}}$ & 0.39 & 0.58 & 0.24 \\
Jurassic shale $^{\mathrm{b}}$ & 0.24 & 0.47 & 0.11 \\
Kimmeridge shale $^{\mathrm{b}}$ & 0.38 & 0.58 & 0.20 \\
Cretaceous shale $^{\mathrm{c}}$ & 0.28 & 0.39 & 0.06 \\
Maikop Clay $^{\mathrm{d}}$ & 0.25 & 0.73 & 0.10 \\
Pirre shale $^{\mathrm{e}}$ & 0.20 & 0.18 & 0.30 \\
Mesaverde Clayshale $^{\mathrm{f}}$ & 0.33 & 0.73 & 0.58 \\
Wills Point Shale $^{\mathrm{f}}$ & 0.22 & 0.32 & 0.28 \\
\hline
\end{tabular}

${ }^{\mathrm{a}}$ Liu et al. (this paper).

${ }^{\mathrm{b}}$ Hornby (1995).

${ }^{\mathrm{c} J o n e s}$ and Wang (1981).

${ }^{\mathrm{d}}$ Slater (1997).

${ }^{\mathrm{e}}$ White et al. (1983).

${ }^{\mathrm{f}}$ Roberson and Corrigan (1983).
The $30 \%$ difference between the horizontal seismic velocity and vertical sonic log velocity cannot be explained simply by the drift expected from the two measurements at different frequencies (sonic logs usually measure velocity at several kilohertz, and the seismics measure velocity between 100 and $400 \mathrm{~Hz}$ in this example). The drift caused by the velocity dispersion is normally less than $10 \%$ and is typically $5 \%$. The only satisfactory explanation for such a difference between the vertical and horizontal velocities is the alignment of clay platelets along the bedding planes (White et al., 1983; Hornby, 1995; Slater, 1997) or direct bedding-induced anisotropy in the Antrim Shale, and such anisotropy is believed to be a common feature in sedimentary rocks (Bush and Crampin, 1991). The strong oscillations in sonic log and gamma ray $\log$ between the depths of $1100 \mathrm{ft}(350 \mathrm{~m})$ and $1210 \mathrm{ft}(370 \mathrm{~m})$ are an indication of shaly sands or sand/shale sequence, possibly the transition between shales in the upper portion (with high gamma rays and low velocity) and sands towards the base (low gamma rays and high velocity).

\section{Crosshole channel wave analysis}

In Fig. 2, we show that there is a good correlation between the channel-wave mode excitations with the velocity variations. The large amplitudes dominate the records in the top parts of the section, corresponding to the low velocity zone between the depth of $940 \mathrm{ft}(286 \mathrm{~m})$ and $1020 \mathrm{ft}(310 \mathrm{~m})$ (Zone A). There is also a correlation of amplitudes and velocity variation between the depth of $1050 \mathrm{ft}(320 \mathrm{~m})$ and 1090 $\mathrm{ft}(330 \mathrm{~m})$ (Zone B), in particular for P-waves. Channel waves are dispersive and attenuative, and are strongly affected by the presence of velocity anisotropy (Liu et al., 1992). A typical example shown in Fig. 4 is an observed P-wave in the XX-component (a) and an S-wave in the YY-component (c) for the receiver at the depth of $1130 \mathrm{ft}(340 \mathrm{~m})$, and the source at the depth 
P-wave
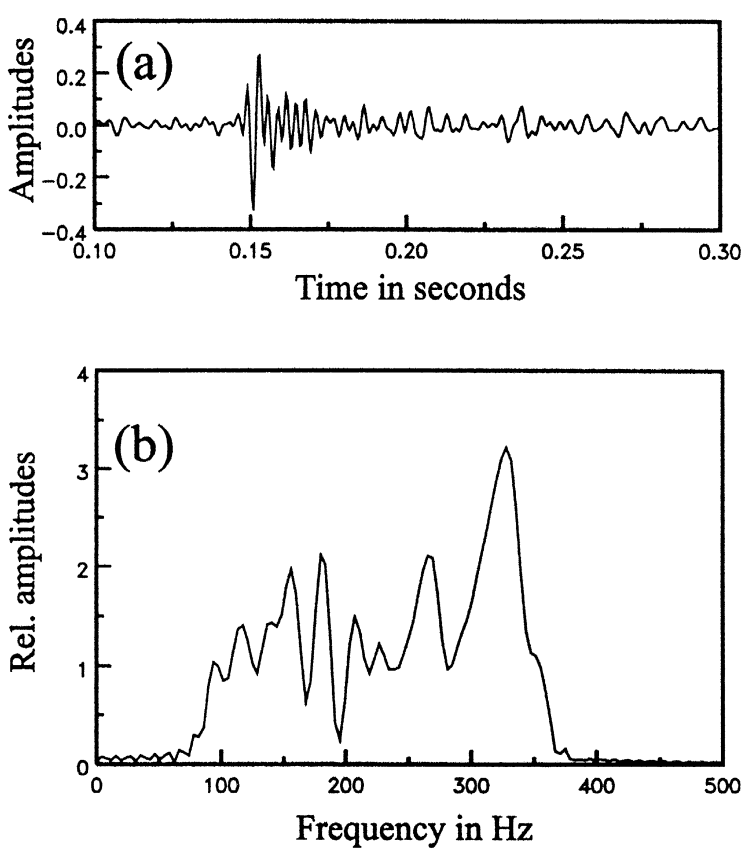

S-wave
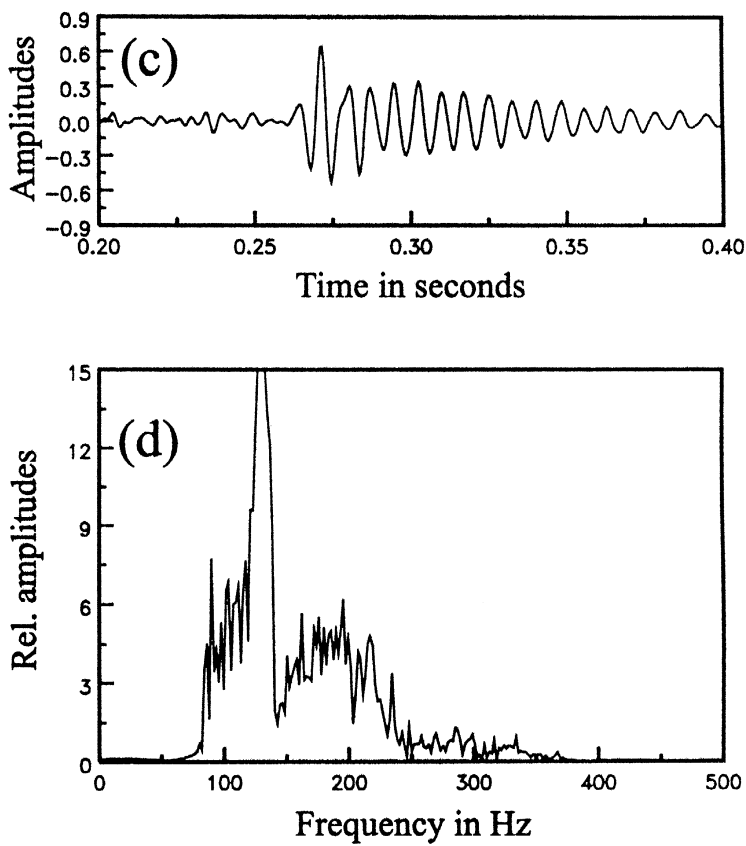

Fig. 4. A typical example of P-wave (a) and S-wave (c) with the corresponding spectra in (b) and (d). The source depth is at $1058 \mathrm{ft}(320 \mathrm{~m})$, and the receiver depth is at $1130 \mathrm{ft}(340 \mathrm{~m})$.

of $1090 \mathrm{ft}(330 \mathrm{~m})$. A comparison of their amplitude spectra is also given in Fig. 4. Typically, the P-wave energy is concentrated between 100 and $350 \mathrm{~Hz}$ with a peak frequency around 250 to $300 \mathrm{~Hz}$, whereas for S-waves, it is about half, i.e., around 100 to $250 \mathrm{~Hz}$ with a peak frequency generally around $120 \mathrm{~Hz}$.

\subsection{Dispersion}

Fig. 5 shows the Dziewonski map of a typical recorded S-wave from YY-component for source at $970 \mathrm{ft}(295 \mathrm{~m})$ and receiver at $986 \mathrm{ft}(300 \mathrm{~m})$ (Dziewonski et al., 1969). The lines are theoretical dispersion curves for an isotropic and TI media and are calculated for a three-layer model using the anisotropic propagation matrix method described in Lou and Crampin (1991). The isotropic channel wave modes are marked A, B and $\mathrm{C}$ corresponding to the fundamental, first higher and second higher Love wave modes on the curves, and similarly the corresponding D, E and $\mathrm{F}$ marks the fundamental, first higher and second Love wave modes in a TI medium. It is seen that the first higher mode Love channel wave from a model with 30\% TIV anisotropy is required to fit the observation as the energy is concentrated around a velocity of $7300 \mathrm{ft} / \mathrm{s}$ $(2230 \mathrm{~m} / \mathrm{s})$. Therefore, dispersion analysis of channel waves provides an estimation of S-wave velocities. The data actually have a narrow frequency range of between 70 and $250 \mathrm{~Hz}$. Nevertheless, the observation does show some pronounced dispersion characteristics, such as the long wavetrain.

\subsection{Attenuation}

One of the noticeable features in the data is the difference in frequency content between Pand $\mathrm{S}$-waves. This is true for the whole dataset, and is clearly demonstrated in Fig. 4. We use the spectral ratio method to estimate the relative attenuation of both the $\mathrm{P}$ - and $\mathrm{S}$-waves. Follow- 
(a)

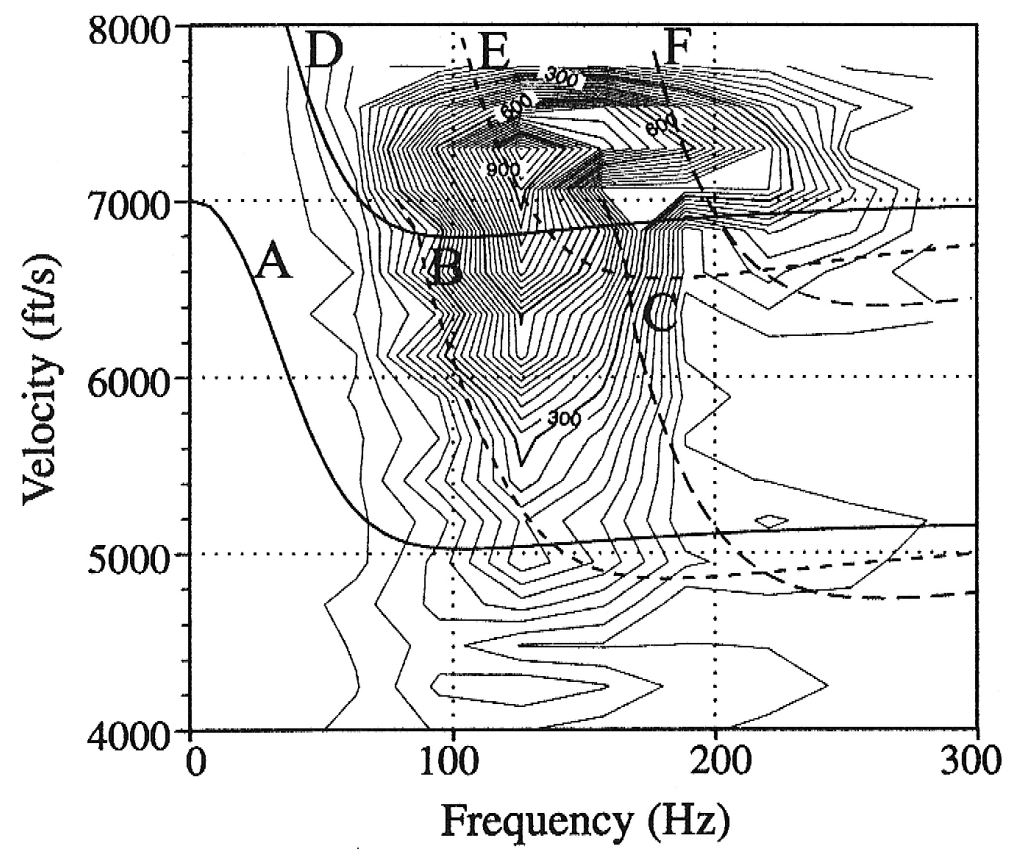

(b)

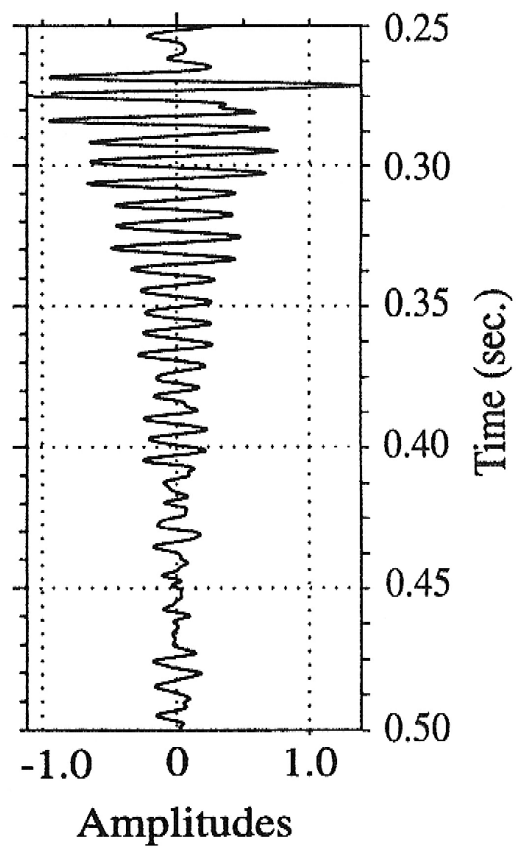

Fig. 5. Dziewonski contour map showing variation of S-wave velocity with frequency for a typical channel wave shown on the right [YY-component with source at $970 \mathrm{ft}(295 \mathrm{~m})$ and receiver at $986 \mathrm{ft}(300 \mathrm{~m})$ ]. Continuous lines are the theoretical Love waves in isotropic (lower 3 lines: A, B and C) and anisotropy with 30\% TIV (top three lines: D, E and F) media. Solid lines are the fundamental mode (A and D), and the dashed lines are the first (short dashed lines: B and E) and second (long dashed lines: $\mathrm{c}$ and $\mathrm{f}$ ) higher modes.

ing Toksöz et al. (1978) and Li and Richwalski (1996), the amplitudes of plane waves for two recorded signals traveling at a distance $x$ can be expressed as:

$$
\begin{aligned}
A_{1}(f)= & G_{1}(x) \exp \left[-\alpha_{1}(f) x\right] \\
& \times \exp [i(\omega t-k x)],
\end{aligned}
$$

and

$$
\begin{aligned}
A_{2}(f)= & G_{2}(x) \exp \left[-\alpha_{2}(f) x\right] \\
& \times \exp [i(\omega t-k x)],
\end{aligned}
$$

where $A$ is amplitude, $f$ is frequency, $k$ is wavenumber, $G(x)$ is a geometrical factor which includes spreading, reflections, etc., and $\alpha(f)$ is the frequency-dependent attenuation coefficient. Subscripts refer to signals 1 and 2. If we assume that $\alpha$ is a linear function of frequency, we can write $\alpha(f)=a f$, where $a$ is constant and related to the quality factor $Q$ by:

$Q=\frac{\pi}{a V}$,

for a given velocity $V$. In the crosshole experiment, as both source and receiver boreholes are vertical, we measure the signal for both source and receiver at the same level, therefore $G_{1}$ and $G_{2}$ are frequency-independent scaling factors. The ratio of Fourier amplitudes is:

$$
\frac{A_{1}}{A_{2}}=\frac{G_{1}}{G_{2}} \exp \left[-\left(a_{1}-a_{2}\right) f x\right],
$$

or

$\ln \left(\frac{A_{1}}{A_{2}}\right)=\ln \left(\frac{G_{1}}{G_{2}}\right)-\left(a_{1}-a_{2}\right) f x$. 
When $G_{1} / G_{2}$ is independent of frequency, $\left(a_{1}\right.$ $-a_{2}$ ) can be found from the slope of the line fitted to $\ln \left(A_{1} / A_{2}\right)$ versus frequency. Since we do not have the source measurement, we use the first recorded trace at the top of the survey as a reference to estimate the relative attenuation. The relative attenuation is then given by:

$\Delta Q^{-1}=Q_{1}^{-1}-Q_{2}^{1}=\frac{V}{\pi}\left(a_{1}-a_{2}\right)$.

In Figs. 6 and 7, a few selected plots of spectral ratio variation with frequency (in log scales) are shown for both $\mathrm{P}$ - and S-waves, respectively. The straight line in each plot is the best linear
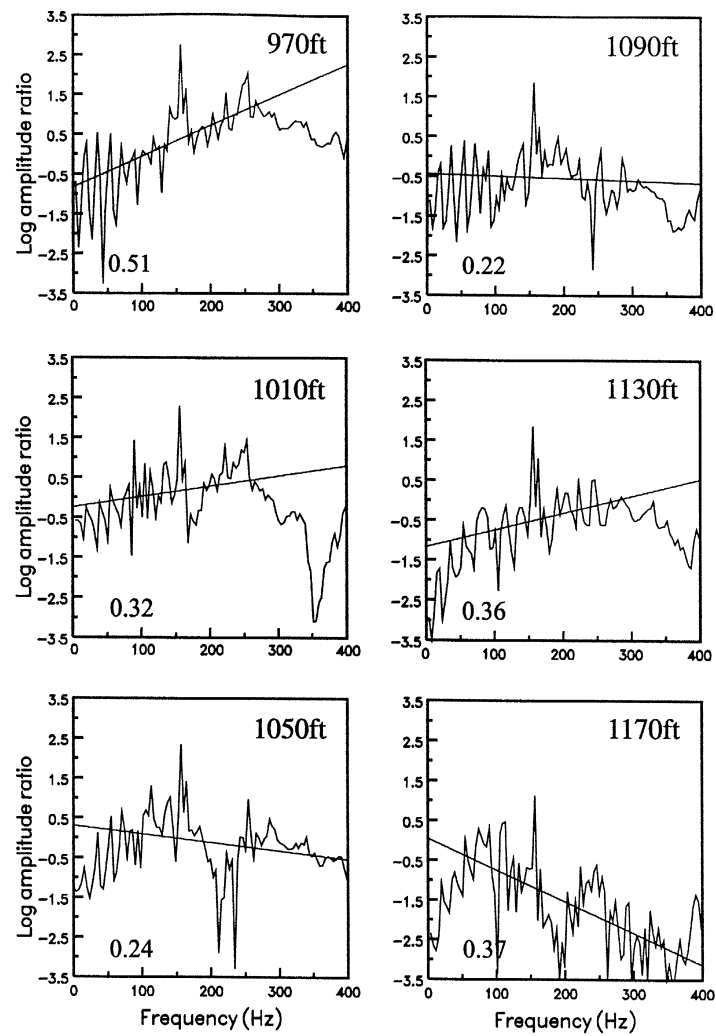

Fig. 6. Variation of logarithmic spectra amplitude ratio with frequency for CHSL P-waves at selected depths. The straight line is the best fit between frequencies of 50 and $300 \mathrm{~Hz}$. The number on the top right corner of each plot denotes the source/receiver depth, and the number on the bottom left corner of each plot indicates the goodness-of-fit normalized to unit standard deviation. The larger the value is, the good the fit is (the maximum value or a perfect fit to linear line should be 1 ).
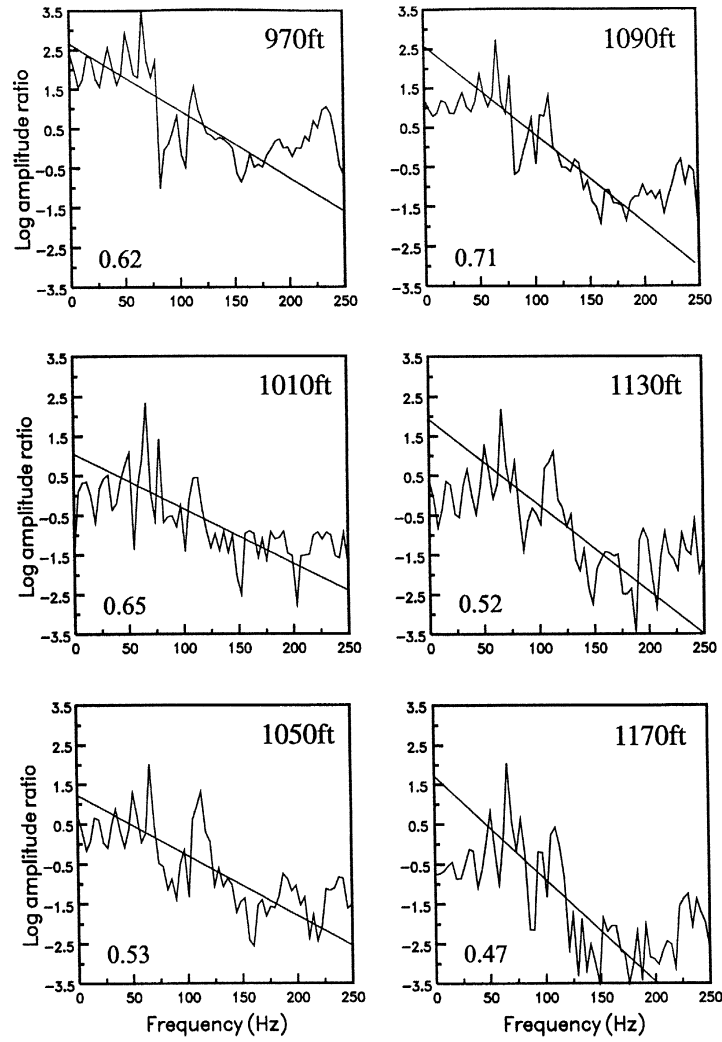

Fig. 7. Variation of logarithmic amplitude ratio with frequency for CHSL S-waves at selected depths. The straight line is the best fit between frequencies of 50 and $200 \mathrm{~Hz}$.

fit to the observed variations, and the relative attenuation can be estimated by the slope of the straight line. For P-waves, we try to fit the lines in the frequency range of 50 to $300 \mathrm{~Hz}$, and for $\mathrm{S}$-waves, we fit the lines between frequencies of 50 and $200 \mathrm{~Hz}$. The number on the bottom left corner of each plot indicates the goodness-of-fit normalized to unit standard deviation (Press et al., 1992). The larger the value is, the good the fit is (the maximum value or a perfect fit to linear line should be 1). In general, the linear fit to the observed log amplitude spectra is better for S-waves than for $\mathrm{P}$-waves. The final estimated relative attenuation variation with depth is given in Fig. 8 with the error bars indicating the standard deviation. There is a large variation of P-wave attenuation with depth, and an almost linear increase in relative attenuation with depth 

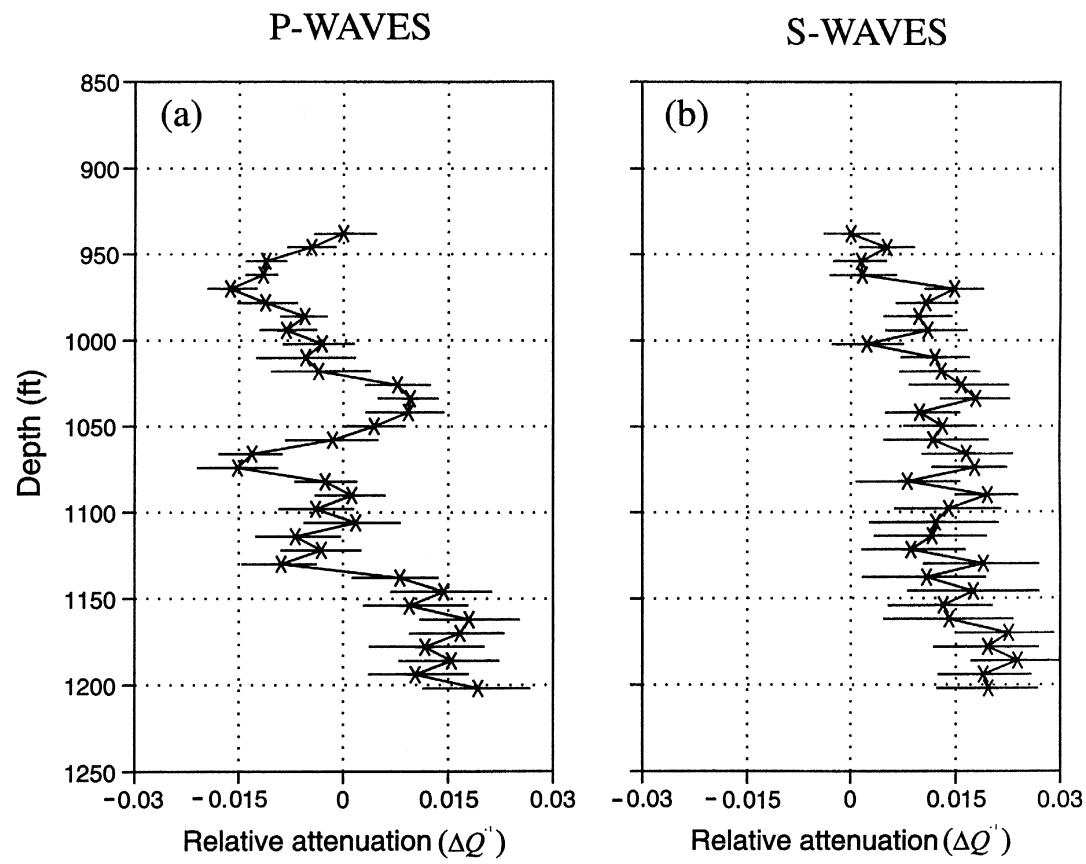

Fig. 8. Variation of the relative attenuation $\Delta Q^{-1}$ with depth. (a) $\mathrm{P}$-waves and (b) $\mathrm{S}$-waves. The error bars mark the standard deviations.

for S-waves. The maximum reduction in amplitudes is equivalent to about $Q^{-1}=30$.

As recorded $\mathrm{S}$-waves have a low frequency content compared with the recorded P-waves, this indicates the stronger attenuation of the $\mathrm{S}$-waves than the P-waves. This could be due to several factors, including the presence of fluids, intrinsic viscoelastic properties and wave scattering. The lithology at the depth covered in the crosshole experiment may be shaly sand, which is characterized by the large variation in the gamma ray logs. Also at this depth interval, we see a general velocity increase with depth. Both are indication of transition between shale and sand. The presence of channel waves has indicated the high degree of bed continuity between the source and the receiver boreholes. However, it is unlikely that a layering effect can account for a strong attenuation of S-waves, but not for P-waves. The strong attenuation associated with $\mathrm{S}$-waves may therefore be attributed to viscoelastic properties of porous shaly sands or scattering by fractures.

\subsection{Polarizations}

A cross-component energy coupling is normally regarded as the first noticeable feature of azimuthal anisotropy. In an earlier study, we found that a simple indication of fracture-induced anisotropy is the presence of coherent energy in the vertical components from SH-type sources (Liu et al., 1991). From Fig. 1, we find that there is very little energy coupled in cross components. One explanation for the overall lack of cross-component coupling of energy may be that the raypaths happen to be parallel or perpendicular to the fracture planes, so that only one mode of shear-waves is excited. Another explanation is that the anisotropy-induced coupling may indeed be small for the near horizontally propagating waves. In a synthetic seismogram study by Lou and Crampin (1991), the energy on radial-components from the $\mathrm{SH}$ source is $5 \%$ to $10 \%$ less than that on the transverse-components even for a crack density of $10 \%$ (for near vertical propagations in VSPs, 
a $10 \%$ anisotropy can introduce a strong coupled energy). A further explanation is that the interwell distance is relatively large, and the small coupled energy may have suffered a significant attenuation.

If fracture-induced azimuthal anisotropy does exist, its combination with layering-induced anisotropy will result in an anisotropy with an orthorhombic symmetry. This was first observed in the Paris Basin (Bush and Crampin, 1991), and is now believed to be a common feature of sedimentary basins. When a weak TIH anisotropy (say 10\%) is combined with a strong TIV anisotropy (say 30\%), the polarizations of the fast split shear-waves in both horizontal (R-T) and vertical (V-T) planes are pre-
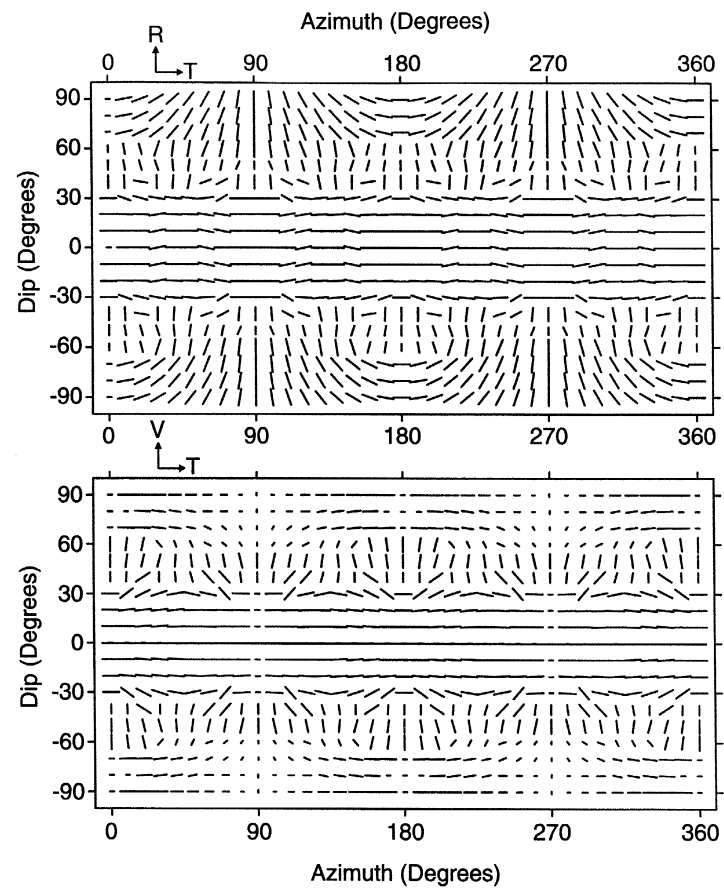

Fig. 9. Plate Carée cylindrical projections of the polarizations of split shear-waves propagating in a medium with combination of 5\% azimuthal anisotropy (TIH) and $30 \%$ TIV anisotropy. It shows the full range of raypath direction from upward $\left(-90^{\circ}\right)$ to downward $\left(90^{\circ}\right)$ to a receiver from azimuth of $0^{\circ}$ to $360^{\circ}$. Polarizations of the leading split shear-waves are projected onto horizontal, marked radial and transverse, and vertical and transverse cross-sections for a fixed amplitude of displacement. The length of the symbols indicates the amplitude of a normalised leading shear-wave for the appropriate direction. dominantly in the transverse direction regardless of the direction of horizontal raypaths relative to the fracture orientation (Fig. 9). Fig. 9 shows the Plate Carée cylindrical projections of the polarizations of split shear-waves propagating in a medium with a combination of $5 \%$ azimuthal anisotropy (TIH) and 30\% TIV anisotropy. It shows the full range of raypath direction from upward $\left(90^{\circ}\right)$ to downward $\left(90^{\circ}\right)$ to a receiver from azimuth of $0^{\circ}$ to $360^{\circ}$. Polarizations of the leading split shear-waves are projected onto horizontal, marked radial and transverse, and vertical and transverse cross-sections for a fixed amplitude of displacement. The length of the symbols indicates the amplitude of a normalised leading shear-wave for the appropriate direction (see Liu et al., 1989; Baptie et al., 1993). This seems to be the case in Fig. 1, where the predominant energy is in the horizontal $\mathrm{T}$ components. The first motions are all in the transverse direction. It thus makes it unlikely that fracture orientations can be predicted from particle-motion analysis alone for near horizontal raypaths.

\section{Synthetic seismogram study}

Since TIV anisotropy is a dominant feature of the observations, we only include TIV anisotropy in our modeling. Synthetic seismograms were generated using the anisotropic reflectivity method of Kennett (1983), which was extended to the full anisotropic media by Booth and Crampin (1983). The model consists of 25 horizontal layers (see Fig. 3). From the horizontal and vertical velocities as shown in Fig. 3, four of the five elastic constants for TIV media $C_{11}$, $C_{33}, C_{66}$ and $C_{44}$ can be determined from Eqs. (1a), (1b), (1c) and (1d). The fifth elastic constant $C_{13}$ was estimated by solving the KelvinChristoffel equation for the off-axis raypaths following Helbig (1994). Attenuation was introduced in the modeling by using estimated relative quality factors in Fig. 8. Since we do not have a measurement of density, we have used 
an average density of 2.3 for shales as listed in Thomsen (1986) to generate synthetic seismograms. However, we believe this is justified and does not affect our final conclusions of this paper. The source function used in calculating the synthetic seismograms is a Ricker wavelet with a peak frequency of $200 \mathrm{~Hz}$. Both in-line $(\mathrm{X})$ and cross-line $(\mathrm{Y})$ sources are used to represent in-line and cross-line source decompositions of the rotary sources.

Fig. 1 shows a typical 6-C common-source gather with the source at a depth of $1002 \mathrm{ft}(305$ $\mathrm{m})$. The corresponding synthetic seismograms for an isotropic model based on the sonic log velocities (solid line in Fig. 2) are shown in Fig.
10. We can see a clear difference in the traveltime between synthetics and observations (by $0.1 \mathrm{~s}$ for $\mathrm{S}$-waves and $0.05 \mathrm{~s}$ for P-waves). A much better fit to the travel-time is given in Fig. 11, computed for a model with a $30 \%$ TIV anisotropy. The large amplitudes in both synthetics and observed records are at shallow receivers. Also present in the synthetic seismograms are the $\mathrm{S}$-waves with a small amplitude in the radial and vertical components from the in-line sources, which are almost absent in the observations. This could be a further confirmation of the strong S-wave attenuation. The variation of S-wave amplitudes with depth in the synthetic seismograms is similar to that of the

\section{Isotropic model}

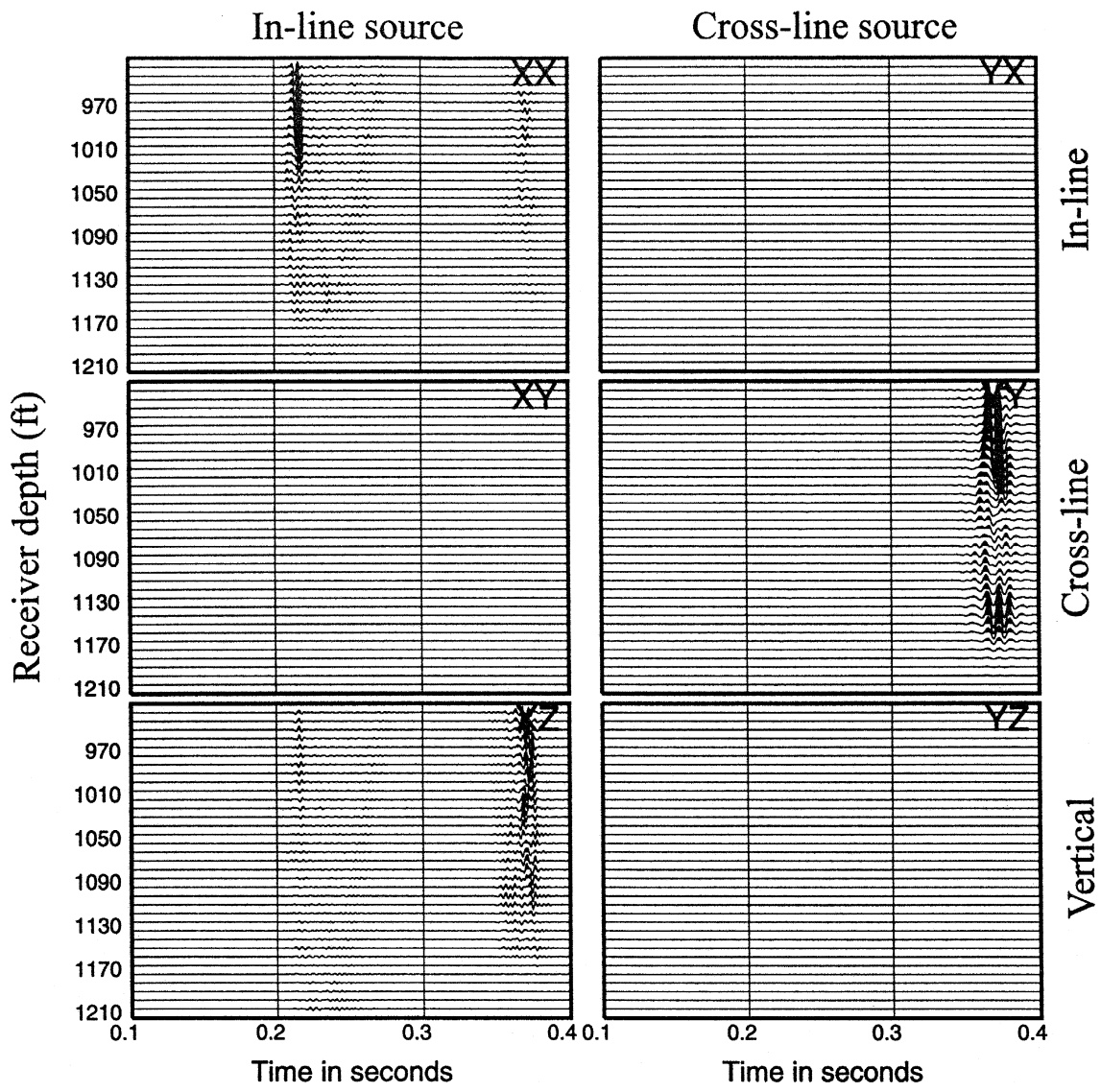

Fig. 10. Synthetic seismograms generated for an isotropic model based on the simplified layered structure in Fig. 4. The velocity profile is taken from the sonic log. 


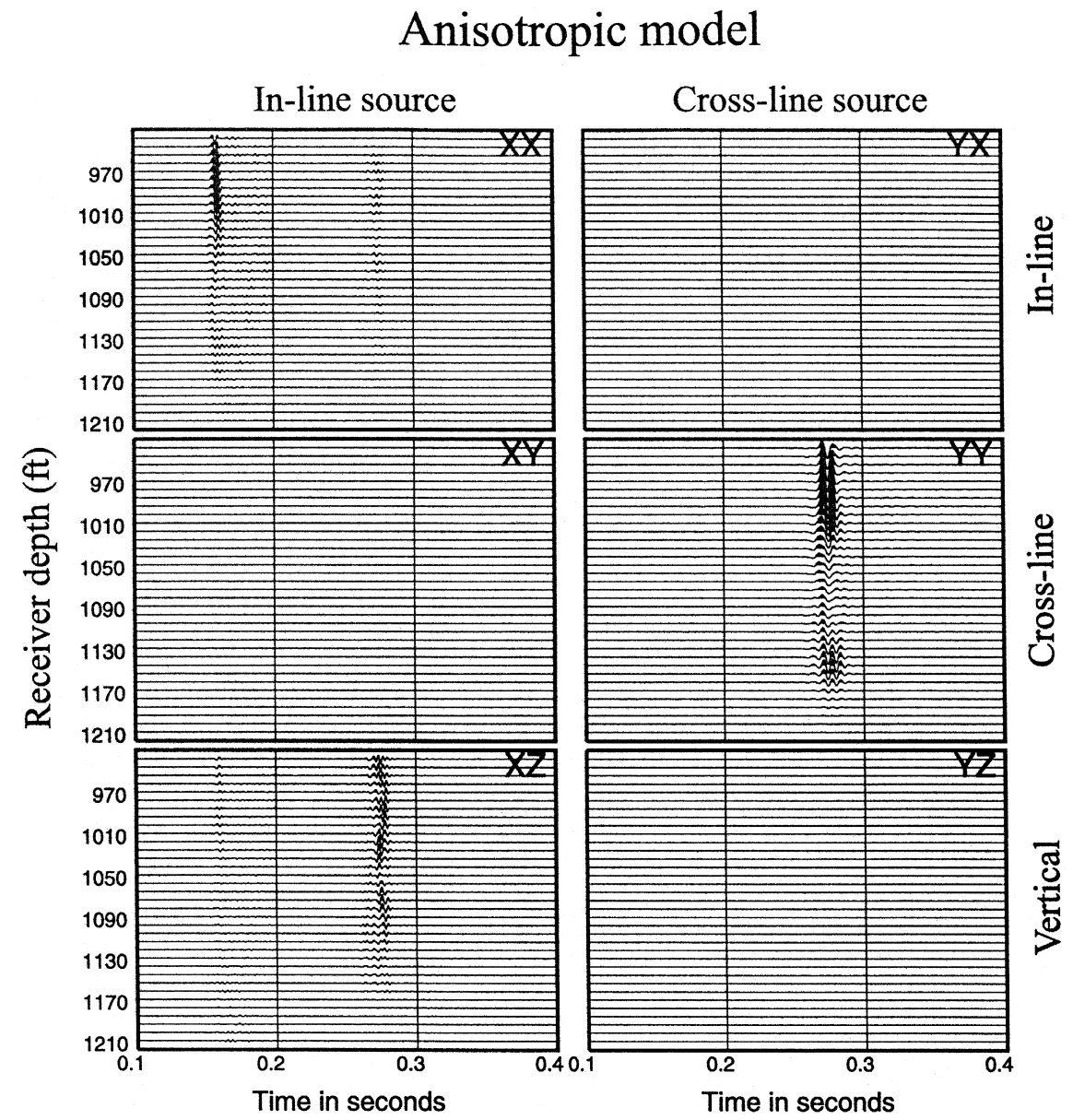

Fig. 11. Same as Fig. 10, but computed for a layered TIV structure with a $30 \%$ anisotropy.

observed data, confirming the need to include the TIV anisotropy in the modeling, and also the channelling phenomenon of the low velocity zones identified in the sonic log.

\section{Conclusions}

We have presented strong evidence of TIV and (less obvious) $\mathrm{TIH}$ anisotropies in the Antrim Shale formation using the analysis of crosshole channel-wave data. The results can be summarized as follows.

(1) A crosshole seismic logging analysis reveals that there is a strong bedding-induced anisotropy over the depth interval covered in this experiment. The horizontal P-velocity is about $30 \%$ higher than the vertical P-velocity. Despite the lack of cross-component coupling, we have nevertheless found evidence of fracture-induced azimuthal anisotropy. Estimation of fracture parameters (orientation and density) have not been possible due to limited data available.

(2) P- and S-waves are well separated in the crosshole data. The dominant $\mathrm{S}$-wave frequency is between 100 and $250 \mathrm{~Hz}$ in contrast to the P-waves, which have a higher frequency of between 100 and $350 \mathrm{~Hz}$. This suggests that $\mathrm{S}$-waves suffer a significant attenuation due to viscoelastic properties of porous shaly sands or scattering by fractures. 
(3) The S-wave data are dominated by channel-wave modes traveling at very high angles, i.e., the wavefront normal is nearly horizontal. Channel waves are characterized by their dispersive nature, and have elliptical particle motions. The observation of channel-wave modes strongly suggests a high degree of bed continuity between the source and receiver wells.

(4) A modeling study using synthetic seismograms has provided strong support to our interpretation. Calculated synthetic seismograms show a similar variation of amplitudes with depth to the observations, confirming the existence of continuous waveguides identified in the sonic log. They also confirm the need to include a 30\% TIV anisotropy in the Antrim Shale formation.

\section{Acknowledgements}

We thank Steve Horne, John Lovell and Colin Slater for comments on the manuscript, and Shiyu Xu (Mobil) for useful discussion. We also thank the editor and two anonymous referees for their constructive comments that improve the readability of this paper. This work was supported by Conoco (UK) through Contract No. GPH-6 and the Natural Environment Research Council (UK), and is published with the approval of Conoco and the Director of the British Geological Survey (NERC).

\section{References}

Baptie, B., Crampin, S., Liu, E., 1993. Displaying shearwave splitting in crosshole surveys for materials with combinations of EDA and PTL anisotropies. Can. J. Explor. Geophys. 29, 227-235.

Booth, D.C., Crampin, S., 1983. The anisotropic reflectivity technique. Theory. Geophys. J. R. Astron. Soc. 72, $755-766$.

Bush, I., Crampin, S., 1991. Paris Basin VSPs. Case history establishing combinations of fine-layer (or litho- logic) anisotropy and crack anisotropy from modeling shear wavefields near point singularities. Geophys. J. Int. 107, 433-447.

Cain, B.A., Kaiser, C.J., Picha, M.G., 1996. Geological setting of the unconventional Antrim gas play, Michigan Basin. Paper presented at the Meeting on Fractured Reservoirs. Geophysical Society of Houston, June 1996.

Cole, J.H., 1997. The orbital vibrator, a new tool for characterizing interwell reservoir space. Leading Edge $11,281-283$.

Dresen, L., Rüter, H., 1994. Seismic Coal Exploration: Part B. In-seam Seismics. Pergamon.

Dziewonski, A., Bloch, S., Landisman, M., 1969. A technique for the analysis of transient seismic signals. Bull. Seismol. Soc. Am. 59, 427-444.

Hardage, B.A., 1992. Crosswell Seismology and Reverse VSP. Geophysical Press, London.

Helbig, K., 1994. Foundation of Elastic Anisotropy for Exploration Seismics. Pergamon.

Hornby, B.E., 1995. The Elastic Properties of Shales. PhD Thesis, Cambridge University.

Jones, L.E., Wang, H.F., 1981. Ultrasonic velocities in Cretaceous shales from the Williston Basin. Geophysics 46, 288-297.

Kennett, B.L.N., 1983. Seismic Wave Propagation in Stratified Media. Cambridge Univ. Press.

Krohn, C.E., 1992. Crosswell continuity logging for oil and gas field application. Leading Edge 11-7, 39-45.

Li, X.P., Richwalski, S., 1996. Seismic attenuation and velocities in the German KTB area. J. Appl. Geophys. 36, 67-76.

Lines, L.R., Kelly, K.R., Queen, J.H., 1992. Channel waves in cross-borehole data. Geophysics 57, 334-342.

Lines, L., Tan, H., Queen, J.H., Rizer, W.D., Buller, P., Cox, D., Sinton, J., Ballard, J., Kokkoros, G., Track, A., Guerendel, P., Harris, J., 1995. Integrated reservoir characterization: beyond tomography. Geophysics 60 , 354-364.

Liu, E., Crampin, S., Booth, D.C., 1989. Shear-wave splitting in crosshole surveys: modeling. Geophysics 54, 57-65.

Liu, E., Crampin, S., Queen, J.H., 1991. Fracture detection using crosshole surveys and reverse vertical seismic profiling at the Conoco Borehole Test Facility, Oklahoma. Geophys. J. Int. 107, 449-463.

Liu, E., Crampin, S., Roth, B., 1992. Modeling channel waves with synthetic seismograms in an in-seam seismic survey. Geophys. Prospect. 40, 513-540.

Lou, M., Crampin, S., 1991. Dispersion of guided waves in thin anisotropic waveguides. Geophys. J. Int. 107, 545-555.

Lou, M., Crampin, S., 1992. Guided-wave propagation between boreholes. Leading Edge 11 (7), 34-37.

Parra, J.O., 1996. Guided seismic waves in layered poro- 
viscoelastic media for continuity logging applications: model studies. Geophys. Prospect. 44, 403-425.

Parra, J.O., Zook, B.J., Collier, H.A., 1996. Interwell seismic logging for continuity at the Gypsy test site, Oklahoma. J. Appl. Geophys. 35, 45-62.

Press, W.H., Teukolsky, S.A., Vetterling, W.T., Flannery, B.P., 1992. Numerical Recipes: The Art of Scientific Computing, 2nd edn. Cambridge Univ. Press.

Roberson, J.D., Corrigan, D., 1983. Radiation patterns of a shear-wave vibrator in near-surface shale. Geophysics 48, 19-26.

Slater, C.P., 1997. Estimation and Modeling of Anisotropy in Vertical and Walkaway Seismic Profiles at Two North Causasus Oil Field. PhD Thesis, Edinburgh University.

Sriram, K.P., DeMartini, D.C., Sims, W.E., Rambow, F.H.K., 1991. Determination of fracture orientation in Antrim Shale from multicomponent seismic data. Ex- panded Abstract Presented at Workshop on Geophysical Methods for Fracture Detection and Estimation, 61st Ann. SEG Int. Mtg., pp. 1643-1644.

Thomsen, L., 1986. Weak elastic anisotropy. Geophysics 51, 1954-1966.

Toksöz, M.N., Johnston, D.H., Timur, A., 1978. Attenuation of seismic waves in dry and saturated rocks: I. Laboratory measurements. Geophysics 44, 681-690.

Turpening, W.R., Chon, Y.T., Peper, R.E.F., Szerbiak, R., Schultz, T., Thielmier, G., Ballard, R., 1992. Detection of bed continuity using crosswell data: Gypsy pilot site study. Proc. Form. Eval. Reservoir Geol. SPE 24710, pp. 503-512.

White, J.E., Martineau-Nicoletis, Monash, C., 1983. Measured anisotropy in Pierre Shale. Geophys. Prospect. 31, 709-725.

Zhong, L., Worthington, M.H., 1994. Modeling crosshole channel waves. J. Seismol. Explor. 3, 21-35. 